\title{
Diagnosing pregnancy status using infrared spectra and milk composition in dairy cows
}

\author{
Hugo Toledo-Alvarado, ${ }^{*}$ Ana I. Vazquez, $†$ Gustavo de los Campos, $†$ Robert J. Tempelman, $\ddagger$ \\ Giovanni Bittante, ${ }^{*}$ and Alessio Cecchinato*1 \\ *Department of Agronomy, Food, Natural Resources, Animals and Environment (DAFNAE), University of Padova, 35020, Legnaro PD, Italy \\ †Department of Epidemiology and Biostatistics, and \\ ‡Department of Animal Science, Michigan State University, East Lansing 48824
}

\section{ABSTRACT}

Data on Holstein $(16,890)$, Brown Swiss $(31,441)$, Simmental $(25,845)$, and Alpine Grey $(12,535)$ cows reared in northeastern Italy were used to assess the ability of milk components (fat, protein, casein, and lactose) and Fourier transform infrared (FTIR) spectral data to diagnose pregnancy. Pregnancy status was defined as whether a pregnancy was confirmed by a subsequent calving and no other subsequent inseminations within $90 \mathrm{~d}$ of the breeding of specific interest. Milk samples were analyzed for components and FTIR full-spectrum data using a MilkoScan FT+ 6000 (Foss Electric, Hillerød, Denmark). The spectrum covered 1,060 wavenumbers (wn) from 5,010 to $925 \mathrm{~cm}^{-1}$. Pregnancy status was predicted using generalized linear models with fat, protein, lactose, casein, and individual FTIR spectral bands or wavelengths as predictors. We also fitted a generalized linear model as a simultaneous function of all wavelengths (1,060 wn) with a Bayesian variable selection model using the BGLR R-package (https://r-forge.r-project.org/projects/bglr/). Prediction accuracy was determined using the area under a receiver operating characteristic curve based on a 10fold cross-validation (CV-AUC) assessment based on sensitivities and specificities of phenotypic predictions. Overall, the best prediction accuracies were obtained for the model that included the complete FTIR spectral data. We observed similar patterns across breeds with small differences in prediction accuracy. The highest CV-AUC value was obtained for Alpine Grey cows (CVAUC $=0.645)$, whereas Brown Swiss and Simmental cows had similar performance $(\mathrm{CV}-\mathrm{AUC}=0.630$ and 0.628, respectively), followed by Holsteins (CV-AUC $=0.607)$. For single-wavelength analyses, important peaks were detected at wn 2,973 to $2,872 \mathrm{~cm}^{-1}$ where Fat-B (C-H stretch) is usually filtered, wn $1,773 \mathrm{~cm}^{-1}$

Received August 8, 2017.

Accepted November 8, 2017.

${ }^{1}$ Corresponding author: alessio.cecchinato@unipd.it where Fat- $\mathrm{A}(\mathrm{C}=\mathrm{O}$ stretch $)$ is filtered, wn $1,546 \mathrm{~cm}^{-1}$ where protein is filtered, wn $1,468 \mathrm{~cm}^{-1}$ associated with urea and fat, wn 1,399 and $1,245 \mathrm{~cm}^{-1}$ associated with acetone, and wn 1,025 to $1,013 \mathrm{~cm}^{-1}$ where lactose is filtered. In conclusion, this research provides new insight into alternative strategies for pregnancy screening of dairy cows.

Key words: Fourier transform infrared spectroscopy, milk, milk component, pregnancy

\section{INTRODUCTION}

Changing metabolic and energy requirements due to pregnancy in cows are likely to also change milk yield and milk composition. For example, a decline in milk yield during gestation in pregnant cows has been reported in several studies, becoming more evident after the third month of pregnancy (Olori et al., 1997; Loker et al., 2009) when the requirements of the fetus demand a significant amount of nutrients (Moe and Tyrrell, 1972). Pregnancy also affects milk composition with an increase of fat, protein, lactose, and casein as pregnancy advances (Olori et al., 1997). Consequently, the effect of pregnancy has been suggested as an adjustment factor to increase the accuracy of genetic evaluations on production traits (Bohmanova et al., 2009). In fact, several countries have included pregnancy stage in their genetic evaluations for milk yield, fat, and protein (Interbull, 2016).

Confirmation of pregnancy in dairy cows is fundamental to successful breeding programs such that early diagnosis tools that would help farmers to determine pregnancy are needed. Current pregnancy diagnosis tests include direct methods (transrectal palpation and ultrasonography) and indirect methods (milk progesterone and pregnancy-associated glycoproteins in blood or milk; Fricke et al., 2016). All these methods are costly, require animal handling, and have limited efficacy. Nonreturn to estrus after insemination is commonly used as a convenient measure of pregnancy success; however, estrus detection depends on several factors, thereby de- 
creasing the reliability of this measure (Senger, 1994). The ideal pregnancy test should be highly sensitive, highly specific, inexpensive, and simple to conduct on farm (Fricke et al., 2016).

Fourier transform infrared (FTIR) spectroscopy is already globally used to routinely assess milk composition in milk recording programs (ICAR, 2016); for instance, FTIR data are routinely used to determine milk components (fat, protein, casein, lactose, TS, urea, citric acid, free fatty acids, and some individual fatty acids), freezing point, $\mathrm{pH}$, and ketosis screening. In addition, FTIR spectroscopy has been used to predict many other detailed phenotypes such as fatty acid profiles, protein fraction compositions, free $\mathrm{AA}$, and milk coagulation properties (De Marchi et al., 2014). Other phenotypes having direct relationships with milk composition have also been studied, such as body energy status and feed and energy intake (McParland and Berry, 2016). In relation to health and fertility of cattle, Bastin et al. (2016) studied the use of FTIR spectroscopy in milk as an effective indicator of health and fertility, associating acetone and BHB with ketosis and associating various fatty acids (e.g., C18:1 cis-9 and C10:0) with fertility. Lainé et al. (2017) reported a direct effect of pregnancy on milk composition of Holsteins and on their milk FTIR spectrum: the absorbance of 212 waves were affected by pregnancy, especially in the infrared spectral region from wavenumber 1,577 to $968 \mathrm{~cm}^{-1}$ (transition from mid- to long-infrared sections of the spectrum). Finally, Lainé et al. (2014) used residuals from spectral data (mid-infrared region) preadjusted for several fixed effects (e.g., parity, breed, month of test day, DIM) to discriminate the residual spectra of open cows from the residual spectra of pregnant cows with high specificity and sensitivity.

What has not yet been studied is the possibility of discriminating between pregnant and open cows simply using whole-spectrum FTIR profiles. Therefore, the objectives of this study were to assess and to compare the prediction accuracies of a reproductive outcome (pregnancy status of dairy cows) using data on milk components (fat, protein, casein, and lactose) indirectly derived from spectral wavelength absorbances as well as direct single-band and whole-spectrum FTIR data.

\section{MATERIALS AND METHODS}

\section{Field Data}

Production and female fertility data were collected from farms in the northeastern Bolzano/Bozen province in Italy by the Breeders Federation of Alto Adige/ Südtirol (Associazione Provinciale delle Organizzazioni
Zootecniche Altotesine/Vereinigung der Südtiroler Tierzuchtverbände, Bolzano/Bozen, Italy). Management systems were rather heterogeneous, ranging from the traditional small farms of the mountainous areas to more modern and larger operations elsewhere. A good description of the dairy farms in the region is provided by Sturaro et al. (2013) and by Stocco et al. (2017a). Milk yield and composition records were obtained from the official milk recording system and consisted of daily milk yield $(\mathrm{kg} / \mathrm{d})$ and of fat, protein, casein, and lactose percentages analyzed from FTIR spectra according to internationally approved methods (ICAR, 2016). Data included records generated from 2010 to 2016 on Holstein, Brown Swiss, Simmental, and Alpine Grey cows.

\section{Data Editing}

The interval between consecutive inseminations was required to be greater than $3 \mathrm{~d}$ in accordance with ICAR (2016) guidelines. Only records made $\leq 91 \mathrm{~d}$ after each insemination were kept because the percentage of open cows was very low by wk 13 after insemination (7, 6,3 , and $3 \%$ for Holstein, Brown Swiss, Simmental, and Alpine Grey, respectively). The proportions of pregnant and open cows by weeks after insemination for each breed are available in Appendix Figure A1. Gestation length was restricted to be within $30 \mathrm{~d}$ from the average for each breed (Holstein $=281 \mathrm{~d}$, Brown Swiss $=$ $290 \mathrm{~d}$, Simmental $=285 \mathrm{~d}$, and Alpine Grey $=287 \mathrm{~d}$ ). The calving interval was restricted to be less than 700 $\mathrm{d}$ for all breeds. Only records with DIM $\leq 305 \mathrm{~d}$ were considered, and parity was classified as $1,2,3$, or $\geq 4$. A detailed description of fertility traits as well as data editing is reported by Toledo-Alvarado et al. (2017).

Pregnancy Definition. A cow's pregnancy status (PS) was coded as a binary variable based on whether a subsequent insemination was not recorded within 90 $\mathrm{d}$ after breeding and confirmed by subsequent calving $(P S=1)$ versus an insemination being registered within the subsequent $90-\mathrm{d}$ period $(\mathrm{PS}=0)$. Otherwise, PS was set to be unknown.

FTIR Spectra. All milk samples were analyzed using a MilkoScan (Foss Electric, Hillerød, Denmark) in the laboratory of the Federazione Latterie Alto Adige/ Sennereiverband Südtirol (Bolzano/Bozen Italy). The spectrum covers from the short-wavelength infrared (SWIR) to the long-wavelength infrared (LWIR) regions with 1,060 spectral points from wavenumber 5,010 to $925 \mathrm{~cm}^{-1}$, which correspond to wavelengths ranging from 1.99 to $10.81 \mu \mathrm{m}$ and frequencies ranging from 150.19 to $27.73 \mathrm{THz}$. The spectrum transmittances $(\mathrm{T})$ were transformed to absorbances $(\mathrm{A})$ with the equation $\mathrm{A}=\log (1 / \mathrm{T})$. A principal component analysis 
Table 1. Total number of cows and insemination records, average pregnancy rates, and descriptive statistics (mean $\pm \mathrm{SD}$ ) for DIM, days open, milk yield, and milk composition for each breed

\begin{tabular}{lcccc}
\hline Item & Holstein & Brown Swiss & Simmental & Alpine Grey \\
\hline Cows (no.) & 16,890 & 31,441 & 25,845 & 12,535 \\
Inseminations (no.) & & & & \\
$\quad$ Total & 88,980 & 176,698 & 150,596 & 73,825 \\
$\quad$ Successful & 60,434 & 121,855 & 117,677 & 78.1 \\
Pregnancy (\%) & 67.9 & 68.9 & & 79.4 \\
Interval trait & & & $142.6 \pm 54.6$ & $142.9 \pm 52.6$ \\
$\quad$ DIM & $164.9 \pm 60.0$ & $158.6 \pm 59.5$ & $119.1 \pm 63.3$ & $118.0 \pm 60.4$ \\
Days open & $156.5 \pm 76.2$ & $148.9 \pm 76.5$ & $24.5 \pm 6.1$ & $17.9 \pm 4.9$ \\
Milk yield (kg/d) & $28.3 \pm 6.6$ & $23.6 \pm 5.9$ & & \\
Milk composition (\%) & & & $3.97 \pm 0.61$ & $3.72 \pm 0.52$ \\
$\quad$ Fat & $3.95 \pm 0.65$ & $4.17 \pm 0.60$ & $3.43 \pm 0.31$ & $3.38 \pm 0.31$ \\
Protein & $3.31 \pm 0.31$ & $3.62 \pm 0.33$ & $2.69 \pm 0.24$ & $2.65 \pm 0.23$ \\
Casein & $2.60 \pm 0.24$ & $2.84 \pm 0.25$ & $4.76 \pm 0.17$ & $4.81 \pm 0.19$ \\
Lactose & $4.76 \pm 0.17$ & $4.76 \pm 0.18$ &
\end{tabular}

was performed on the FTIR spectra with Mahalanobis distances calculated from the first 5 principal component scores. The probability level for the chi-squared distribution of a sample's Mahalanobis distance was calculated from the incomplete gamma function with 5 degrees of freedom. Samples with a probability level $<0.01$ were considered to be outliers and removed from the data set (Shah and Gemperline, 1989). To explore spectra variation over time, the first 5 principal components were plotted over time and inspected. Major shifts were detected in different year periods; therefore, to overcome the spectral variations the absorbance values for every wave were centered to a null mean and standardized to a unit sample variance within year periods. After editing, the number of records with milk production, composition, FTIR spectrum, and fertility information per breed was 88,980 for Holstein, 176,698 for Brown Swiss, 150,596 for Simmental, and 73,825 for Alpine Grey (Table 1).

\section{Statistical Analysis}

Calibration Models. Separate analyses for each breed, including different effects in the model, were used to predict the PS of cows. First, PS was predicted using milk components, one component at a time (fat, protein, casein, and lactose), with and without the inclusion of the effects of parity and DIM. Then the PS was predicted using each of the 1,060 spectral points, one wavelength at a time. Finally, we included the complete FTIR spectra and then the complete FTIR spectra along with parity and DIM effects to predict PS. The description of the covariates included in each model, labeled as models 1 through 12 , is provided in Table 2. All of our analyses were based on a generalized linear model with a probit link function. Specifically, at the underlying liability level, we assumed a linear model of the form

$$
l_{i}=\beta_{0}+\sum_{j=1}^{p} \beta_{j} x_{i j}+\varepsilon_{i},
$$

where $\beta_{0}$ is an intercept, $\left[x_{i 1}, x_{i 2}, \ldots, x_{i p}\right]$ represent the covariates (or dummy variables derived from it in the case of categorical predictors) listed in Table $2, \beta_{j}=$ $\left(\beta_{1}, \ldots, \beta_{p}\right)^{\prime}$ are the effects of the covariates, and $\varepsilon_{i}$ is an error term assumed to be independent and identically distributed with mean zero and unit variance. The classification rule was set to $\left\{y_{i}=1\right.$ if $l_{i}>0 ; 0$ otherwise\}. Therefore,

$$
\operatorname{Pr}\left(y_{i}=1 \mid x_{i}\right)=\operatorname{Pr}\left(l_{i}>0 \mid x_{i}\right)=\Phi\left(\beta_{0}+\sum_{j=1}^{p} \beta_{j} x_{i j}\right),
$$

where $\operatorname{Pr}\left(y_{i}=1 \mid x_{i}\right)$ is the response probability of being pregnant for PS, $\operatorname{Pr}\left(l_{i}>0 \mid x_{i}\right)$ is the liability threshold, and $\Phi($.$) represents the cumulative distribution func-$ tion of the standard normal distribution.

Models 1 through 9 include predictors whose numbers were small relative to the total sample size, and therefore effects were estimated for these models by maximum likelihood using the GLM function of R. On the other hand, models 10 through 12 included a large numbers of predictors. In these cases, effects were estimated using a Bayesian model using Markov chain Monte Carlo methods with the effects of covariates (DIM, parity, and year) treated as fixed and with the effects of the FTIR spectrum and herd treated as random. Specifically, following Ferragina et al. (2015), we used a mixture prior with a point of mass at zero and a $t$-slab for spectrum effects based on a modified version of model Bayes B (Meuwissen et al., 2001), whereas for herd effects we used Gaussian priors as implemented 
in the BGLR R-package (Pérez and De Los Campos, 2014). For models 10 through 12, a total of 50,000 Markov chain Monte Carlo samples were drawn, with the first 10,000 discarded as burn-in.

Assessment of Prediction Accuracy. Sensitivity (TPr), defined as TPr $=$ true positives/(true positives + false negatives) and specificity (FPr), defined as FPr $=$ true negatives/(false positives + true negatives), are the most commonly used measures of classification accuracy. However, both measures depend on the decision threshold such that as the threshold increases, the number of TPr and FPr both monotonically increase. The projection of these pairs on a plane defines a curve, often referred to as the receiver operating characteristic (ROC) curve, which is typically used to assess the performance of a diagnostic tool (Fawcett, 2006). The most common ROC summary measure is the area under the ROC curve (AUC), denoted as

$$
\mathrm{AUC}=\frac{1}{m n} \sum_{i=1}^{m} \sum_{j=1}^{n} 1_{p_{i}>p_{j}},
$$

where $i$ runs over all $m$ data points having a true positive classification and $j$ runs over all $n$ data points having a true negative classification; $p_{i}$ and $p_{j}$ denote the probability score assigned by classifier to data points $i$ and $j$. For interpretation, the AUC is the probability that a classifier will rank a randomly chosen true positive instance higher than a randomly chosen true negative case. Because the AUC is a portion of the area of the unit square, its value will always be between 0 and 1 , where an AUC of 0.5 is a random guess (Fawcett, 2006). Therefore, to assess the performance of milk components and FTIR spectra as a diagnosis tool of PS of cows, the cross-validation AUC (CV-AUC) was estimated as a summary metric between the predictions and the phenotypes in the testing sets of the 10-fold cross-validation with the $\mathrm{R}$ package pROC (Robin et al., 2011). All models were compared using Wilcoxon's test (paired tests corrected with false discovery rate method for multiple testing adjustments for the number of models compared) applied to the CV-AUC achieved by each model. In addition, each CV-AUC mean was tested (Wilcoxon's test) for whether it was greater than 0.5 , which is the CV-AUC of a random classifier. For the individual wavelength analysis, a Manhattan plot was created for each breed with the $-\log _{10}(P$-value) of the wavelength effect corrected with the false discovery rate method for the number of wavelengths (Figure 1). All data editing and statistical analysis were done in the $\mathrm{R}$ environment (R Core Team, 2016).

\section{RESULTS AND DISCUSSION}

\section{Fertility, Milk Yield, and Composition}

Table 1 shows the number of cows and insemination records for the 4 breeds analyzed. The average number of records per cow was 5.6 for Brown Swiss $(\mathrm{n}=176,698)$, 5.8 for Simmental $(\mathrm{n}=150,596), 5.2$ for Holstein $(\mathrm{n}=$ $88,980)$, and 5.8 for Alpine Grey $(\mathrm{n}=73,825)$ across parities. Additionally, the proportion of pregnant and open cows by weeks after insemination is available for each breed in Appendix Figure A1. The pregnancy rate was more than 10 percentage points higher for the dualpurpose breeds Simmental (78.1\%) and Alpine Grey (79.4\%) compared with the specialized dairy breeds Holstein (67.9\%) and Brown Swiss (68.9\%). Fertility of dairy and dual-purpose breeds responds differently to the variation of milk productivity in terms of both herd average and individual cow production within the herd (Toledo-Alvarado et al., 2017). Similar pregnancy rates have been obtained by Tiezzi et al. $(2011,2015)$ on a different data set relative to Brown Swiss cows in the same mountainous area.

Table 2. Effects included in each model for the prediction of pregnancy status

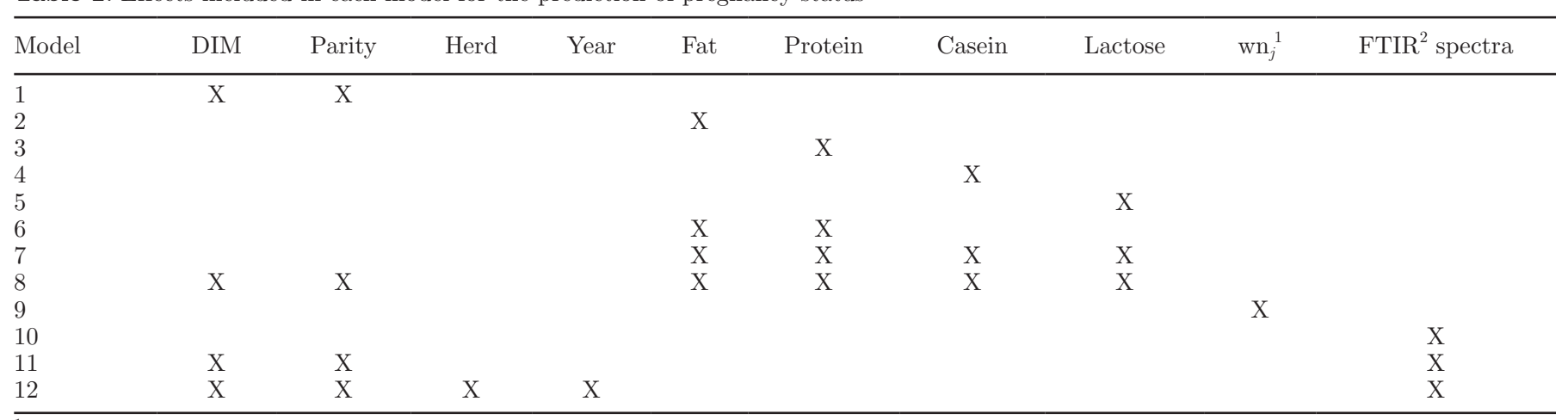

${ }^{1} \mathrm{wn}_{j}=$ individual wavenumbers $(j=1, \ldots, 1,060)$ fitted separately for a total of 1,060 different analyses for model 9.

${ }^{2} \mathrm{FTIR}=$ Fourier transform infrared. 
Descriptive statistics for milk yield and components used for predicting PS are presented in Table 1. Holstein cows had the highest milk production but the lowest content of protein, casein, and lactose. Relative to the Holstein cows, the Brown Swiss cows had a lower daily milk yield $(-16 \%)$ but higher percentages of fat $(+5 \%)$, protein $(+9 \%)$, and casein $(+9 \%)$. The dual-purpose Simmental cows had a slightly greater milk production than the Brown Swiss cattle and lower milk contents. The Alpine Grey cows had the lowest mean milk yield $(-36 \%)$ but similar milk composition relative to the Holstein cows. These differences are likely due to both breed-specific genetic and herd management conditions (Stocco et al., 2017a, b). For example, Holstein cows are generally reared within intensive dairy management systems (farms using freestall housing, milking
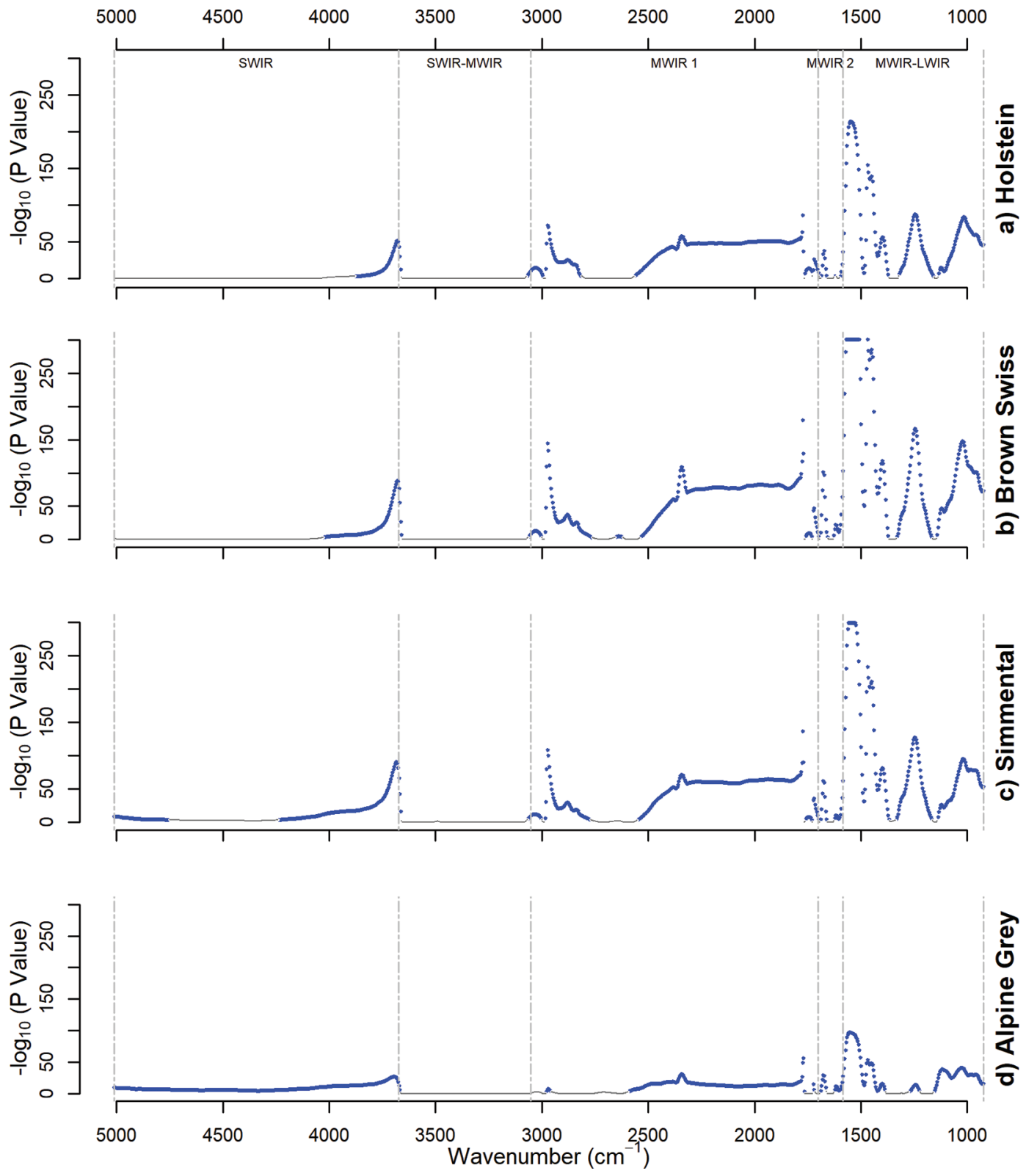

Figure 1. Manhattan plot of $-\log _{10}(P$-value $)$ for single-wavelength absorbance associations across the entire Fourier transform infrared spectrum (1,060 wavelengths) on pregnancy status (PS) of (a) Holstein, (b) Brown Swiss, (c) Simmental, and (d) Alpine Grey cows. Blue dots indicate significant associations (false discovery rate $<0.05)$ of the single wavenumber on PS $(P<0.001)$; gray dots are nonsignificant wavenumbers $(P \geq 0.001)$. SWIR $=$ short-wavelength infrared or near-infrared $(1.40-3.0 \mu \mathrm{m}) ;$ MWIR $=$ mid-wavelength infrared $(3.0-8.0 \mu \mathrm{m}) ; \mathrm{LWIR}=$ long-wavelength infrared $(8.0-15.0 \mu \mathrm{m})$. Color version available online. 
parlors, and TMR), whereas the Alpine Grey cows are typically are raised on traditional farms (tiestalls, hay feed supplemented with some concentrates, and so on). Conversely, Brown Swiss and Simmental cows can be found in both types of dairy management systems. More details on different farming systems in the Alps have been reported by Sturaro et al. (2013).

\section{Diagnosis of PS According to Milk Composition}

The CV-AUC for all the prediction models was estimated between predicted and observed PS for each fold created in the cross-validation procedure. Then the mean, minimum, and maximum CV-AUC were estimated, and the results for the 4 breeds are presented in Table 3.

Using just the fat content of milk as a predictor showed a trivial increase of $\mathrm{CV}$-AUC with respect to the value (0.500) expected for a random classifier, whereas lactose content was only slightly more informative. On the contrary, protein content was informative for predicting PS, whereas casein content yielded slightly lower CV-AUC values than protein $(P<0.05)$. A model jointly fitting fat and protein had a predictive ability similar to that of protein or casein alone, further indicating that fat content did not give valuable information for predicting PS once differences in protein had already been accounted for. Similarly, the addition of casein and lactose only mildly increased CV-AUC. A model with cow parity number and DIM had a higher predictive ability compared with the use of a model based just on milk components (fat, protein, casein, and lactose) regardless of whether each component was fitted alone or combined with each other. However, when all of these terms were combined together into one model, predictive ability was only slightly improved compared with the models including only milk components (Table 3).

We are not aware of any previous work on the prediction of PS from milk components. Nevertheless, pregnancy has been observed to affect milk composition (Olori et al., 1997; Loker et al., 2009); therefore, milk composition should be useful for the diagnosis of PS. However, the prediction accuracy of PS is limited and seems useful only for preliminary screening. Prediction of PS directly from milk composition seems more practical than a model that also considers information on cow parity and DIM because these data sources are often disconnected.

It is also interesting to note that the rankings of predictive abilities of different models were similar across the 4 breeds tested (Table 3) despite their widely different production levels, genetic backgrounds, and management conditions. Also, CV-AUC values were similar

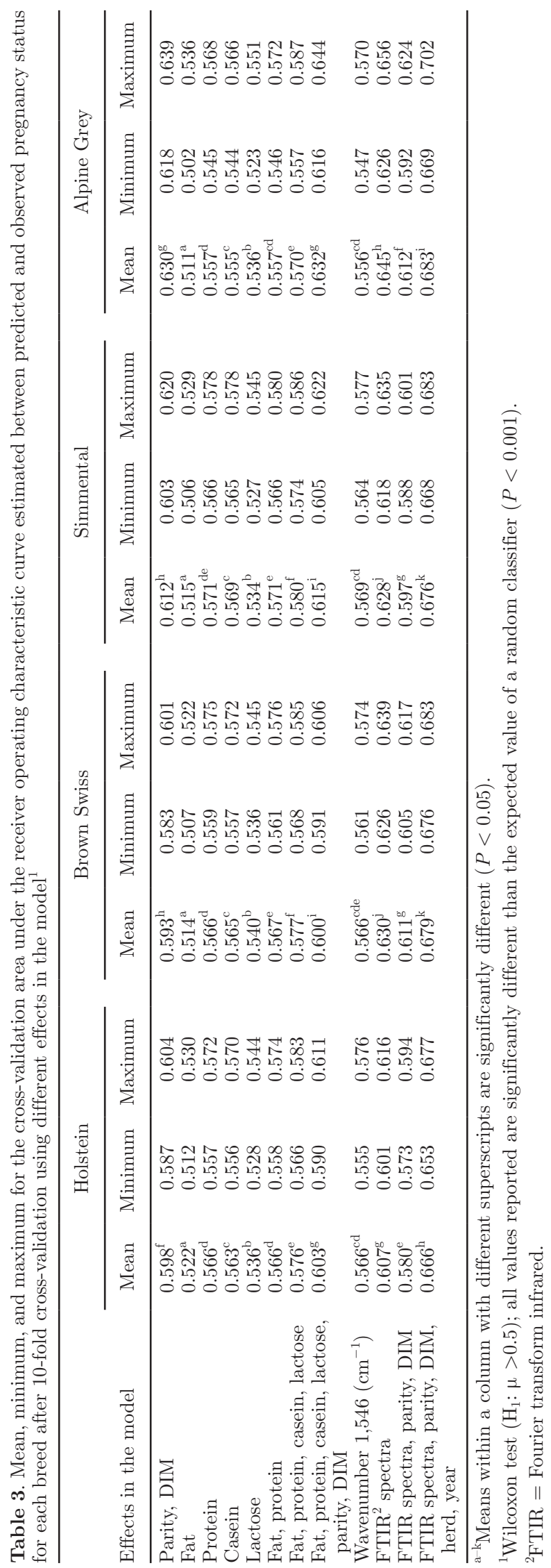

Journal of Dairy Science Vol. 101 No. 3, 2018 
for all models based on milk components, even though higher CV-AUC were noted for Simmental and Alpine Grey cows compared with Holstein and Brown Swiss cows when the model included both milk composition and other cow-specific information (parity and DIM).

\section{Association of PS to Individual Wavelength Absorbances of Milk FTIR Spectrum}

Milk composition is generally estimated either based on the absorbance of milk at specific infrared wavelengths (Kaylegian et al., 2006) or based on the entire absorbance spectrum using specific chemometrics procedures (ICAR, 2016). In our study, we predicted PS directly from the absorbance of milk spectra as well as using milk composition inferred by spectral data to, in turn, predict PS. As described later, the absorbance at wavenumber $1,546 \mathrm{~cm}^{-1}$ was the single best wavenumber predictor of PS and hence is included in Table 3. In this region, protein is usually filtered from $1,546 \mathrm{~cm}^{-1}$ $(6.46 \mu \mathrm{m})$ to $1,492 \mathrm{~cm}^{-1}(6.70 \mu \mathrm{m}$; Kaylegian et al., 2006; Lynch et al., 2006). Therefore, it is not surprising that the CV-AUC of this wavenumber was similar to the values obtained with the models that included protein or casein.

The milk FTIR absorbance measures of individual wavelengths or the whole spectra in the mid-infrared range can be used to predict phenotypes (e.g., milk composition; Karoui et al., 2010). Several chemical bonds are responsible for the absorption of electromagnetic radiations at specific wavelengths in the area of SWIR and MWIR (Bittante and Cecchinato, 2013). A preliminary analysis was carried out to associate each individual wavelength, based on the graphical representation of the $-\log _{10}(P$-value $)$ obtained by the 1,060 models (1 for each wavelength) to predict PS. The Manhattan plot is presented in Figure 1. One can easily identify the specific regions with important associations with PS noting that the magnitude of $-\log _{10}(P$-value) is a measure of the strength of such associations. The SWIR (or near-infrared) region ranging from wavenumber 5,010 to $3,673 \mathrm{~cm}^{-1}$ (wavelengths 2.00 to $2.72 \mu \mathrm{m}$ ) has no specific chemical bonds related to milk (Soyeurt et al., 2011; Bittante and Cecchinato, 2013). However, a small significant peak was observed around the individual wavenumber $3,683 \mathrm{~cm}^{-1}$ (wavelength $2.72 \mu \mathrm{m}$ ) at the border between the SWIR and SWIR-MWIR regions of the spectrum. In this same area, Bittante and Cecchinato (2013) found a decrease of estimated genetic variances and heritabilities of absorbance. Nevertheless, this wavelength is very close to those known for characterizing the bonds $\mathrm{C}=\mathrm{CH}_{2}$ and $\mathrm{O}-\mathrm{H}$ (typical of alcohols, phenols, and carboxylic acids). The region
SWIR-MWIR (transition between near-infrared and mid-infrared) extends from wavenumber 3,669 to 3,052 $\mathrm{cm}^{-1}$ (wavelengths 2.73 to $3.28 \mu \mathrm{m}$ ) and is known for being affected by a very high variance of absorbance due to the water content of milk. This region is often excluded from chemometrics for predicting milk components. In this area, inferred associations were seemingly nonimportant [i.e., small $-\log _{10}(P$-values $\left.)\right]$, so it could be also excluded for prediction of PS.

The MWIR-1 region (mid-infrared) spans from 3,048 to $1,701 \mathrm{~cm}^{-1}$ (corresponding to wavelengths 3.28 to $5.88 \mu \mathrm{m}$ ); this area is important for prediction of fat. The major absorbance peaks detected are bonds: $\mathrm{C}-\mathrm{H}$, $\mathrm{C}=\mathrm{O}, \mathrm{C}-\mathrm{N}$, and $\mathrm{N}-\mathrm{H}$ (Bittante and Cecchinato, 2013). In this region, some peaks with mildly strong associations with PS were detected. The first important bandwidth was located between 2,973 and $2,872 \mathrm{~cm}^{-1}$ (wavelengths 3.36 to $3.48 \mu \mathrm{m}$ ). In this region, Fat-B [absorbance by the carbon-hydrogen stretch $(\mathrm{C}-\mathrm{H})$ ] is usually filtered $\left[2,873\right.$ to $2,777 \mathrm{~cm}^{-1}$ (3.48 to $\left.3.60 \mu \mathrm{m}\right)$; Kaylegian et al., 2006; Lynch et al., 2006]. Furthermore, in this same bandwidth, Lainé et al. (2017) found that the effect of pregnancy was higher than that of milk fat content at an early stage of pregnancy. Then, after a gradual increase of strength of inferred associations [i.e., $-\log _{10}(P$-values $\left.)\right]$, the Manhattan plot reached a flat region of prediction between 2,344 and $1,777 \mathrm{~cm}^{-1}$ (wavelengths 4.27 to $5.63 \mu \mathrm{m}$ ).

Another notable wavenumber in this region is 1,773 $\mathrm{cm}^{-1}(5.64 \mu \mathrm{m})$ within this MWIR-1 region, where the so-called Fat-A [absorbance by the ester carbonyl stretch $(\mathrm{C}=\mathrm{O})$ ] usually is filtered from 1,785 to 1,747 $\mathrm{cm}^{-1}$ (wavelengths 5.60 to $5.72 \mu \mathrm{m}$ ) and used to predict fat content using a single small spectrum fraction (Kaylegian et al., 2006; Lynch et al., 2006). The small MWIR-2 region covers from 1,698 to $1,586 \mathrm{~cm}^{-1}$ (corresponding to wavelengths 5.89 to $6.31 \mu \mathrm{m}$ ), and it is related to the absorbance of water and $\mathrm{H}-\mathrm{O}-\mathrm{H}$ bending. These features increase the variability of coefficients for the transmittance among different milk samples, thereby decreasing the statistical power for association with PS such that no important peaks were detected here.

The last MWIR-LWIR region (from mid- to longinfrared) spans from wavenumber interval 1,582 to 925 $\mathrm{cm}^{-1}$ (corresponding to wavelengths 6.32 to $10.81 \mu \mathrm{m}$ ) and is the so-called fingerprint area. This region had the highest $-\log _{10}(P$-values $)$ for single wavelengths. This region harbors several peaks of absorbance relative to bonds: $\mathrm{C}-\mathrm{H}$, aromatic $\mathrm{C}=\mathrm{C}, \mathrm{C}-\mathrm{O}$, and $\mathrm{N}-\mathrm{O}$ (Bittante and Cecchinato, 2013). The most important signal for the prediction of PS was found at $1,546 \mathrm{~cm}^{-1}$ $(6.46 \mu \mathrm{m})$, where the protein is usually filtered from 
$1,546 \mathrm{~cm}^{-1}(6.46 \mu \mathrm{m})$ to $1,492 \mathrm{~cm}^{-1}(6.70 \mu \mathrm{m}$; Kaylegian et al., 2006; Lynch et al., 2006). Lainé et al. (2017) described a relative effect of pregnancy from this same wavelength to be bigger than that of the protein content itself in the early stage of pregnancy.

Within the MWIR-LWIR region, the second most important wavenumber is $1,468 \mathrm{~cm}^{-1}(6.81 \mu \mathrm{m})$, which has been associated with urea at $1,469 \mathrm{~cm}^{-1}(6.81 \mu \mathrm{m})$ and fat at $1,460 \mathrm{~cm}^{-1}(6.85 \mu \mathrm{m}$; Hansen, 1998). The next 2 peaks, $1,399 \mathrm{~cm}^{-1}(7.15 \mu \mathrm{m})$ and $1,245 \mathrm{~cm}^{-1}$ $(8.03 \mu \mathrm{m})$, are related to acetone predictions $[1,238$ $\mathrm{cm}^{-1}(8.08 \mu \mathrm{m})$; Hansen, 1999]. Finally, the last set of important wavelengths is located from $1,025 \mathrm{~cm}^{-1}(9.76$ $\mu \mathrm{m})$ to $1,013 \mathrm{~cm}^{-1}(9.87 \mu \mathrm{m})$, close to the region where lactose usually is filtered $\left[1,040 \mathrm{~cm}^{-1}(9.62 \mu \mathrm{m})\right.$; Kaylegian et al., 2006; Lynch et al., 2006]. Also, in this case, the values obtained for the 4 breeds tested were very similar, demonstrating that the relationship between spectrum and PS is primarily based on basic physiological functions (e.g., variation in milk composition due to pregnancy) and are not breed specific. These consistencies hold despite the differences in both milk yield and composition as well as fertility among the different breeds.

\section{Diagnosis of PS According to Whole-Milk FTIR Spectrum}

The second approach consisted of using all wavelengths of the FTIR spectrum (1,060 absorbance values for each milk sample) as predictors of PS in a Bayes B model (Pérez and De Los Campos, 2014). The absorbance at some waves is characterized by the effect of specific chemical bonds; thus, a procedure based on variable selection and shrinkage seems to present some advantages with respect to a statistical approach based on principal components analyses, such as the frequently used partial least squares procedure, especially for complex traits like PS. Ferragina et al. (2015) compared the Bayesian ridge regression, Bayes A, Bayes B, and partial least squares models, obtaining the highest prediction accuracy using the Bayes B model for the prediction of complex traits.

The use of the entire spectrum increased the CVAUC estimate in all the breeds (Table 3) compared with those achieved using individual wavelengths, the milk components (fat, protein, casein, and lactose), and milk components with the inclusion of cow information (parity and DIM). In fact, integrating parity and DIM together with the spectral data exerted a negative effect, slightly depressing the CV-AUC values in all breeds. Conversely, a model including fat, protein, casein, and lactose increased the CV-AUC when par- ity and DIM were also included, demonstrating that these effects are more informative when using the milk components alone but not as important as the complete FTIR spectrum for prediction purposes. However, when the effects of year and herd were included together with the FTIR spectrum, this led to the greatest CV-AUC values, with the maximum value observed for Alpine Grey cows (0.683). This was expected because the differences between herds and years were taken into account, yet one should recognize that this additional information might not be readily available for real-time predictions.

Using just the FTIR-Spectra, the Alpine Grey cows with a CV-AUC of 0.645 were the best classifier of PS, followed by Brown Swiss and Simmental breeds (0.630 and 0.628 , respectively); the lowest value for FTIR spectrum was observed in Holstein cows with 0.607. These results show that, among the models tested, the entire FTIR spectrum without any other supplemental information allows informative pregnancy predictions. This means that predictions could be directly provided by properly calibrated FTIR spectrophotometry on milk samples already routinely analyzed for their chemical composition (fat and protein) without additional costs and time. The possibility of practical application for pregnancy screening requires further research for improving the basic knowledge of the relationships between milk infrared spectrum and physiological changes in lactating cows following conception and for improving the predictive ability of spectral data.

\section{CONCLUSIONS}

Predicting PS using milk FTIR spectra is difficult because of its complicated nature, yet PS is a phenotype indirectly correlated with milk composition. We demonstrated that milk composition, especially its contents of protein and casein, has low but positive predictive ability for PS and that the use of the entire FTIR spectrum further increases the accuracy of prediction. Nevertheless, the inclusion of year and herd together with the FTIR spectrum led to the greatest CV-AUC values; however, it must be considered that this additional covariate information might not always be available for timely predictions. The usefulness of these predictions seems somewhat limited with low CV-AUC for practical use in the routine milk labs. Nevertheless, this study showed that some important regions in the milk spectrum are useful for predictions of PS and facilitate a deeper understanding of the complex relationships between the milk spectrum, milk composition, and the physiological status of the cows. Fourier transform infrared signals seem to have 
similar effects within the same regions within various breeds of dairy and dual-purpose cows evaluated here. Furthermore, various parts of the spectrum were seen to be associated with PS, somewhat revealing which components of milk composition could be more affected in early pregnancy. The potential of FTIR spectrum as an extra tool for the farmer for diagnosis of PS in cows requires further research to improve the accuracy of prediction and to implement the methodologies in farming conditions.

\section{ACKNOWLEDGMENTS}

This research was supported by USDA National Institute of Food and Agriculture (Washington, DC) Agriculture and Food Research Initiative grant 2017-6700725947 and the National Institutes of Health (Rockville, MD) grant R01 GM 101219. We thank the Associazione Provinciale delle Organizzazioni Zootecniche Altoatesine/Vereinigung der Südtiroler Tierzuchtverbände and the Federazione Latterie Alto Adige/Sennereiverband Südtirol (Bolzano/Bozen, Italy) for providing the data. Hugo Toledo-Alvarado received financial support from the Mexican National Council for Science and Technology (Ciudad de México, México).

\section{REFERENCES}

Bastin, C., L. Théron, A. Lainé, and N. Gengler. 2016. On the role of mid-infrared predicted phenotypes in fertility and health dairy breeding programs. J. Dairy Sci. 99:4080-4094. https://doi.org/10 $.3168 /$ jds.2015-10087.

Bittante, G., and A. Cecchinato. 2013. Genetic analysis of the Fouriertransform infrared spectra of bovine milk with emphasis on individual wavelengths related to specific chemical bonds. J. Dairy Sci. 96:5991-6006. https://doi.org/10.3168/jds.2013-6583.

Bohmanova, J., J. Jamrozik, and F. Miglior. 2009. Effect of pregnancy on production traits of Canadian Holstein cows. J. Dairy Sci. 92:2947-2959. https://doi.org/10.3168/jds.2008-1782.

De Marchi, M., V. Toffanin, M. Cassandro, and M. Penasa. 2014. Invited review: Mid-infrared spectroscopy as phenotyping tool for milk traits. J. Dairy Sci. 97:1171-1186. https://doi.org/10.3168/ jds.2013-6799.

Fawcett, T. 2006. An introduction to ROC analysis. Pattern Recognit. Lett. 27:861-874. https://doi.org/10.1016/j.patrec.2005.10.010.

Ferragina, A., G. de los Campos, A. I. Vazquez, A. Cecchinato, and G. Bittante. 2015. Bayesian regression models outperform partial least squares methods for predicting milk components and technological properties using infrared spectral data. J. Dairy Sci. 98:8133-8151. https://doi.org/10.3168/jds.2014-9143.

Fricke, P. M., A. Ricci, J. O. Giordano, and P. D. Carvalho. 2016 Methods for and implementation of pregnancy diagnosis in dairy cows. Vet. Clin. North Am. Food Anim. Pract. 32:165-180. https://doi.org/10.1016/j.cvfa.2015.09.006.

Hansen, P. W. 1998. Urea determination in milk using Fourier transform infrared spectroscopy and multivariate calibration. Milchwissenschaft 53:251-255.

Hansen, P. W. 1999. Screening of dairy cows for ketosis by use of infrared spectroscopy and multivariate calibration. J. Dairy Sci. 82:2005-2010. https://doi.org/10.3168/jds.S0022-0302(99)75437 $-8$.
ICAR (International Committee for Animal Recording). 2016. International Agreement of Recording Practices-Recording Guidelines. ICAR, Rome, Italy.

Interbull. 2016. National genetic evaluation forms provided by countries. Accessed Feb. 7, 2017. http://www.interbull.org/ib/geforms.

Karoui, R., G. Downey, and C. Blecker. 2010. Mid-infrared spectroscopy coupled with chemometrics: A tool for the analysis of intact food systems and the exploration of their molecular structure-quality relationships-A review. Chem. Rev. 110:6144-6168. https:// doi.org/10.1021/cr100090k.

Kaylegian, K. E., G. E. Houghton, J. M. Lynch, J. R. Fleming, and D. M. Barbano. 2006. Calibration of infrared milk analyzers: Modified milk versus producer milk. J. Dairy Sci. 89:2817-2832.

Lainé, A., C. Bastin, C. Grelet, H. Hammami, F. G. Colinet, L. M. Dale, A. Gillon, J. Vandenplas, F. Dehareng, and N. Gengler. 2017. Assessing the effect of pregnancy stage on milk composition of dairy cows using mid-infrared spectra. J. Dairy Sci. 100:28632876. https://doi.org/10.3168/jds.2016-11736.

Lainé, A., H. Bel Mabrouk, L.-M. Dale, C. Bastin, and N. Gengler. 2014. How to use mid-infrared spectral information from milk recording system to detect the pregnancy status of dairy cows. Commun. Agric. Appl. Biol. Sci. 79:33-38.

Loker, S., F. Miglior, J. Bohmanova, J. Jamrozik, and L. R. Schaeffer. 2009. Phenotypic analysis of pregnancy effect on milk, fat, and protein yields of Canadian Ayrshire, Jersey, Brown Swiss, and Guernsey breeds. J. Dairy Sci. 92:1300-1312. https://doi.org/10 $.3168 /$ jds.2008-1425.

Lynch, J. M., D. M. Barbano, M. Schweisthal, and J. R. Fleming. 2006. Precalibration evaluation procedures for mid-infrared milk analyzers. J. Dairy Sci. 89:2761-2774. https://doi.org/10.3168/jds .S0022-0302(06)72353-0.

McParland, S., and D. P. Berry. 2016. The potential of Fourier transform infrared spectroscopy of milk samples to predict energy intake and efficiency in dairy cows. J. Dairy Sci. 99:4056-4070. https://doi.org/10.3168/jds.2015-10051.

Meuwissen, T. H. E., B. J. Hayes, and M. E. Goddard. 2001. Prediction of total genetic value using genome-wide dense marker maps. Genetics 157:1819-1829.

Moe, P. W., and H. F. Tyrrell. 1972. Metabolizable energy requirements of pregnant dairy cows. J. Dairy Sci. 55:480-483. https:// doi.org/10.3168/jds.S0022-0302(72)85519-X.

Olori, V. E., S. Brotherstone, W. G. Hill, and B. J. McGuirk. 1997. Effect of gestation stage on milk yield and composition in Holstein Friesian dairy cattle. Livest. Prod. Sci. 52:167-176. https://doi .org/10.1016/S0301-6226(97)00126-7.

Pérez, P., and G. De Los Campos. 2014. Genome-wide regression and prediction with the BGLR statistical package. Genetics 198:483495. https://doi.org/10.1534/genetics.114.164442.

R Core Team. 2016. R: A Language and Environment for Statistical Computing. R Foundation for Statistical Computing, Vienna, Austria.

Robin, X., N. Turck, A. Hainard, N. Tiberti, F. Lisacek, J.-C. Sanchez, and M. Müller. 2011. pROC: An open-source package for R and $\mathrm{S}+$ to analyze and compare ROC curves. BMC Bioinformatics 12:77. https://doi.org/10.1186/1471-2105-12-77.

Senger, P. L. 1994. The estrus detection problem: New concepts, technologies, and possibilities. J. Dairy Sci. 77:2745-2753. https://doi .org/10.3168/jds.S0022-0302(94)77217-9.

Shah, N. K., and P. J. Gemperline. 1989. A program for calculating Mahalanobis distances using principal component analysis. Trends Analyt. Chem. 8:357-361.

Soyeurt, H., F. Dehareng, N. Gengler, S. McParland, E. Wall, D. P. Berry, M. Coffey, and P. Dardenne. 2011. Mid-infrared prediction of bovine milk fatty acids across multiple breeds, production systems, and countries. J. Dairy Sci. 94:1657-1667. https://doi.org/ 10.3168/jds.2010-3408.

Stocco, G., C. Cipolat-Gotet, T. Bobbo, A. Cecchinato, and G. Bittante. 2017a. Breed of cow and herd productivity affect milk composition and modeling of coagulation, curd firming, and syneresis. J. Dairy Sci. 100:129-145. https://doi.org/10.3168/jds.2016-11662. 
Stocco, G., C. Cipolat-Gotet, V. Gasparotto, A. Cecchinato, and G. Bittante. 2017b. Breed of cow and herd productivity affect milk nutrient recovery in curd, and cheese yield, efficiency and daily production. Animal 12:434-444. https://doi.org/10.1017/ S1751731117001471.

Sturaro, E., E. Marchiori, G. Cocca, M. Penasa, M. Ramanzin, and G. Bittante. 2013. Dairy systems in mountainous areas: Farm animal biodiversity, milk production and destination, and land use. Livest. Sci. 158:157-168. https://doi.org/10.1016/j.livsci.2013.09.011.

Tiezzi, F., C. Maltecca, A. Cecchinato, and G. Bittante. 2015. Comparison between different statistical models for the prediction of direct genetic component on embryo establishment and survival in
Italian Brown Swiss dairy cattle. Livest. Sci. 180:6-13. https://doi .org/10.1016/j.livsci.2015.06.029.

Tiezzi, F., C. Maltecca, M. Penasa, A. Cecchinato, Y. M. Chang, and G. Bittante. 2011. Genetic analysis of fertility in the Italian Brown Swiss population using different models and trait definitions. J. Dairy Sci. 94:6162-6172. https://doi.org/10.3168/jds.2011-4661.

Toledo-Alvarado, H., A. Cecchinato, and G. Bittante. 2017. Fertility traits of Holstein, Brown Swiss, Simmental, and Alpine Grey cows are differently affected by herd productivity and milk yield of individual cows. J. Dairy Sci. 100:8220-8231. https://doi.org/10 .3168/jds.2016-12442.

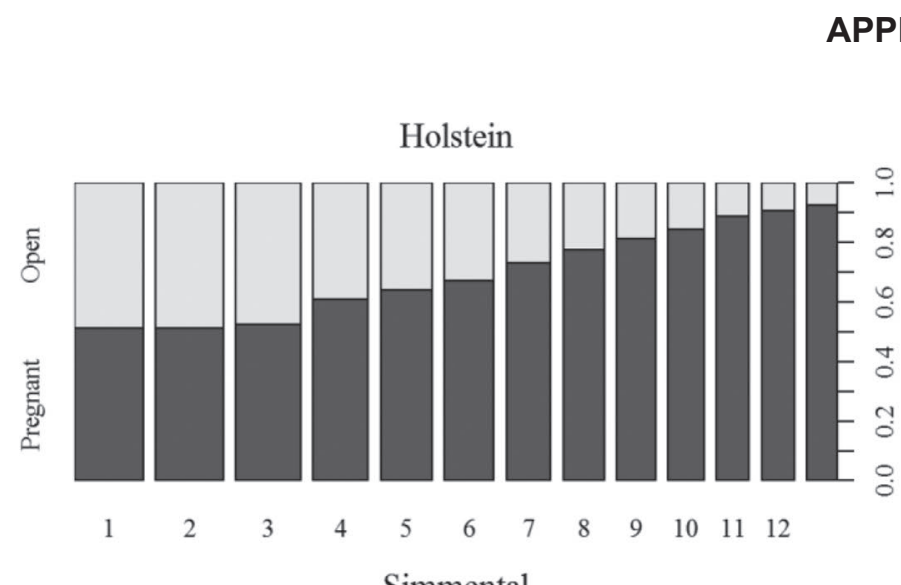

APPENDIX
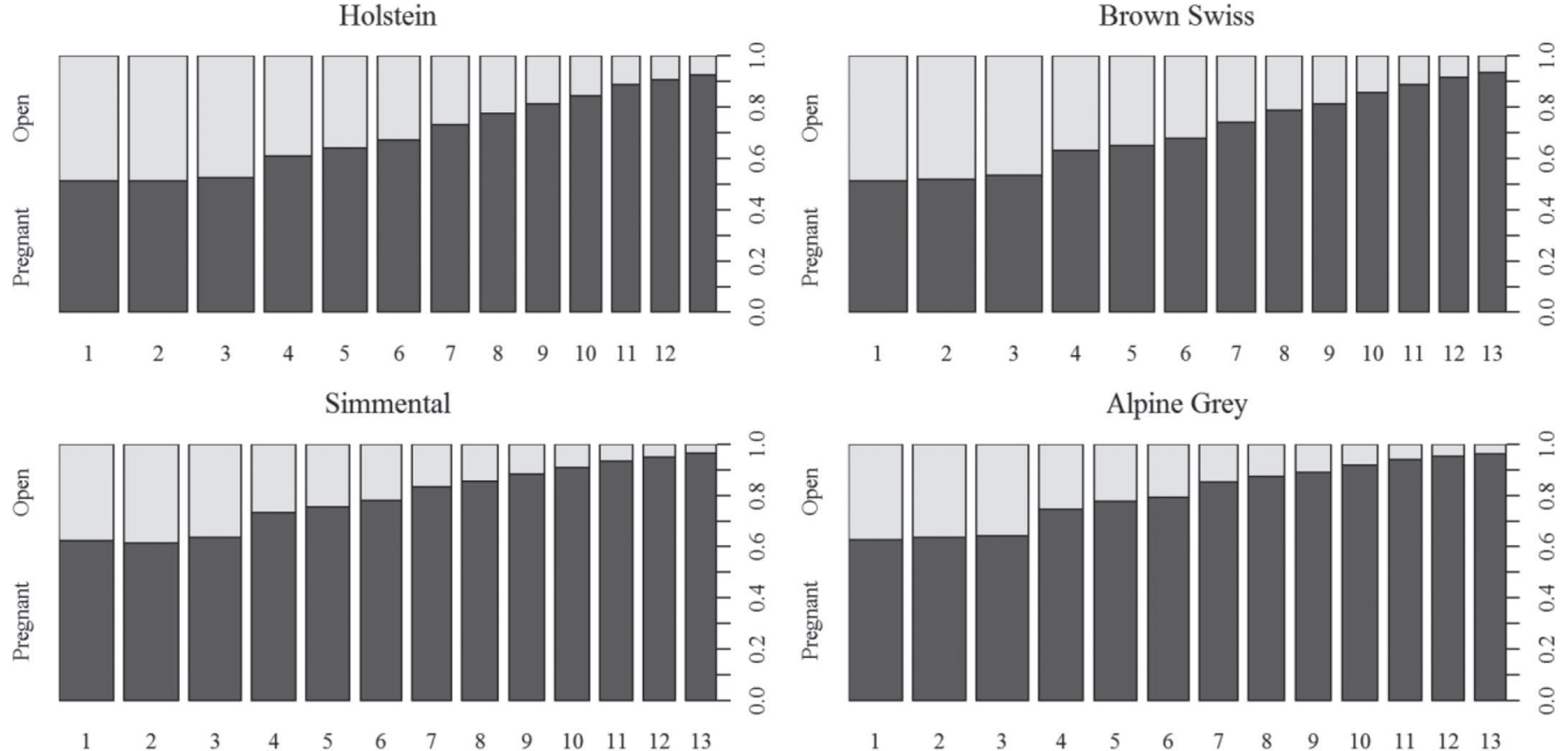

Weeks after Insemination

Figure A1. The proportion of cows that are pregnant and open by weeks after each insemination by breed. 